\title{
Neural mechanisms of impaired fear inhibition in posttraumatic stress disorder
}

\author{
Tanja Jovanovic ${ }^{1 *}$ and Seth Davin Norrholm ${ }^{1,2}$ \\ ' Department of Psychiatry and Behavioral Sciences, Emory University School of Medicine, Atlanta, GA, USA \\ 2 Mental Health Service Line, Veterans Affairs Medical Center, Decatur, GA USA
}

Edited by:

Luke R. Johnson, Uniformed Services University of the Health Sciences, USA

\section{Reviewed by:}

Steven A. Kushner, Erasmus Medical Center, Netherlands

Bram Vervliet, Katholieke Universiteit Leuven, Belgium

\section{*Correspondence:}

Tanja Jovanovic, Department of Psychiatry and Behavioral Sciences, Emory University School of Medicine, 49 Jesse Hill Jr. Drive, Atlanta, GA 30303, USA.

e-mail: tjovano@emory.edu
Posttraumatic stress disorder (PTSD) can develop in some individuals who are exposed to an event that causes extreme fear, horror, or helplessness (APA, 1994). PTSD is a complex and heterogeneous disorder, which is often co-morbid with depression, substance abuse, and anxiety disorders such as panic or social phobia. Given this complexity, progress in the field can be greatly enhanced by focusing on phenotypes that are more proximal to the neurobiology of the disorder. Such neurobiological intermediate phenotypes can provide investigative tools to increase our understanding of the roots of the disorder and develop better prevention or intervention programs. In the present paper, we argue that the inhibition of fear responses is an intermediate phenotype that is related to both the neurocircuitry associated with the disorder, and is linked to its clinical symptoms. An advantage of focusing on fear inhibition is that the neurobiology of fear has been well investigated in animal models providing the necessary groundwork in understanding alterations. Furthermore, because many paradigms can be tested across species, fear inhibition is an ideal translational tool. Here we review both the behavioral tests and measures of fear inhibition and the related neurocircuitry in neuroimaging studies with both healthy and clinical samples.

Keywords: PTSD, fear inhibition, extinction, fear neurocircuitry, neuroimaging

\section{NEUROBIOLOGICAL INTERMEDIATE PHENOTYPES OF PTSD}

Posttraumatic stress disorder (PTSD) can develop in some individuals who are exposed to an event that causes extreme fear, horror, or helplessness (APA, 1994). PTSD is considered the fourth most common psychiatric disorder, affecting $10 \%$ of all men and $18 \%$ of women (Breslau et al., 1998). The rates of lifetime PTSD are closer to $40 \%$ in high trauma populations, such as combat (Kessler et al., 1995) and low-income inner-city populations (Schwartz et al., 2005; Alim et al., 2006). Recent studies have demonstrated a steep dose-response curve between trauma frequency and PTSD symptom severity such that the more traumatic events a person experiences, the greater the PTSD symptoms (Binder et al., 2008; Mcteague et al., 2010). Even at such high prevalence rates, the relationship between trauma exposure and PTSD suggests resiliency in the majority of individuals, indicating the presence of "resilience factors" that allow trauma-related symptoms to diminish over time. These factors can be genetic, as shown by several recent gene by environment interaction studies (Binder et al., 2008; Ressler et al., 2010), or psychological, such positive social support (Charney, 2004; Norrholm and Ressler, 2009).

Delineating these resilience factors is of great importance to the development of improved and personalized treatment approaches to this disorder; however, using the DSM-IV defined disorder as the phenotype under investigation raises many complications. PTSD is a heterogeneous disorder, which presents with different symptom domains, specifically, re-experiencing, avoidance and numbing, and hyper-arousal symptoms. As some patients may present higher symptoms in one domain as compared to another, a one-size-fitsall approach is often inadequate (Norrholm and Jovanovic, 2010).
Furthermore, the neurobiological underpinnings of the different symptoms may not overlap (Lanius et al., 2006), suggesting that different "subtypes" of PTSD may have different treatment targets. Finally, PTSD is frequently co-morbid with other disorders, such as depression, substance abuse, and other anxiety disorders (Kessler et al., 1995). Taken together, these issues result in a complex phenotype of PTSD; one that is difficult to model in animal research and does not easily lend itself to treatment outcome studies.

Given this complexity, progress in the field can be greatly enhanced by focusing on phenotypes that are more proximal to the neurobiology of the disorder. Such neurobiological intermediate phenotypes can provide investigative tools to increase our understanding of the roots of the disorder and develop better prevention or intervention programs. Although the narrow focus cannot by definition encompass the entire spectrum of the illness, it can define targets in the neurocircuitry of the illness.

In the present paper, we argue that the inhibition of fear responses is an intermediate phenotype that is related to both the neurocircuitry associated with the disorder, and is linked to its clinical symptoms. An advantage of focusing on fear inhibition is that the neurobiology of fear has been well investigated in animal models providing the necessary groundwork in understanding alterations. Furthermore, because many paradigms can be tested across species, fear inhibition is an ideal translational tool. For example, fear-potentiated startle and inhibition of fear-potentiated startle has been tested in rodents, non-human primates, as well as humans (Myers et al., 2009). Here we review both the behavioral tests and measures of fear inhibition and the related neurocircuitry in neuroimaging studies with both healthy and clinical samples. 


\section{INHIBITION OF FEAR AS A NEUROBIOLOGICAL PHENOTYPE}

Inhibition of fear responses involves learning and then appropriately responding to safety signals, i.e., the ability to discriminate between danger and safety cues and suppress fear responses in the presence of safety cues (Jovanovic et al., 2011). In the laboratory, fear inhibition can be measured by first using a fear conditioning paradigm to acquire learned fear (termed fear acquisition), which is then followed by training to inhibit learned fear responses (termed fear inhibition). Fear conditioning is based on a simple Pavlovian conditioning model in which a neutral conditioned stimulus (termed the CS; for example, a light) is paired with an aversive unconditioned stimulus (termed the US; for example, cutaneous electric shock). After a number of pairings, the association is formed so that the CS alone elicits the conditioned response (termed the CR; for example, freezing in rodents or fear-potentiated startle in humans; Pavlov, 1927). This basic model is used in animal as well as human research to investigate mechanisms of fear expression (Davis, 1990; Labar et al., 1995; Grillon and Davis, 1997; Fanselow and Ledoux, 1999; Lissek et al., 2005; Jovanovic et al., 2006). The advantage of using these paradigms is that they can be measured with peripheral outcomes such as the skin conductance or startle responses, which are non-invasive but offer physiological measures of fear conditioning. In this review we will describe fear inhibition as the reduction of fear responses in the presence of safety cues which is a manifestation of the underlying inhibitory neurocircuitry.

There are two laboratory models that have been primarily used for behavioral testing of fear inhibition in animals and humans: extinction and differential conditioning. Whereas fear acquisition refers to learning that something is dangerous, extinction is a mechanism by which an individual learns that something that was previously dangerous has become safe. In fear extinction paradigms, a stimulus that was previously paired with an aversive stimulus (the CS+) is then repeatedly presented without the US, so that it no longer elicits a fear response [cf. (Myers et al., 2006; Norrholm et al., 2006), see Figure 1A]. In a basic differential conditioning paradigm, the above CS+ pairing is intermingled, at the time of training, with a separate stimulus (CS-). The CS- does not co-occur with an aversive stimulus, and thus represents safety, or inhibition of fear. This paradigm involves a simple discrimination between the danger and safety cues (see Figure 1B), and is the one most commonly used in human fear conditioning research (Lissek et al., 2005). More complex tasks, such as conditional discrimination, Figure 1C (in which there is an element of the conditioning stimulus that is shared between the CS+ and CS-), and stimulus generalization, Figure 1D (in which there is a perceptual gradient of stimuli between the CS+ and CS-), are designed to capture more subtle variation in fear-inhibition processes.

Conditioned inhibition involves a variation of discrimination in which the danger cue (i.e., CS+) is not reinforced when preceded by (or combined with) a second cue, usually termed X, so that CS+, CS/ $\mathrm{X}-$ ). Although the $\mathrm{X}$ cue should be conditioned to designate safety, it is vulnerable to second-order conditioning effects and limited by configural processing (Myers and Davis, 2004). This paradigm has been used in several animal studies (Falls et al., 1997; Gewirtz et al., 1997), but rarely in human studies (Grillon and Ameli, 2001) due to the above issues. Conditional discrimination, a modification
A EXTINCTION

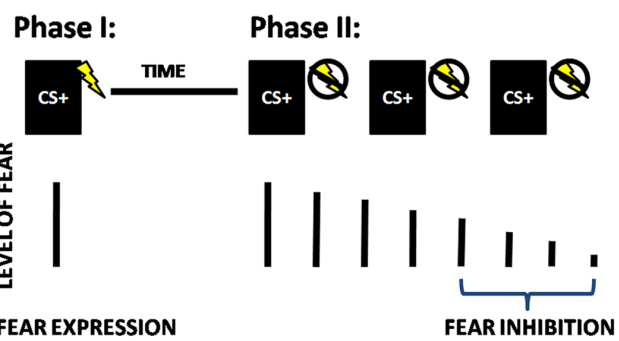

FEAR EXPRESSION

FEAR INHIBITION

B SIMPLE DISCRIMINATION

Phase I:
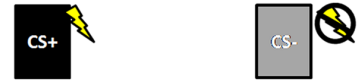

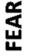

耑

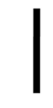

FEAR EXPRESSION FEAR INHIBITION

C CONDITIONAL DISCRIMINATION

Phase I:

Phase II:
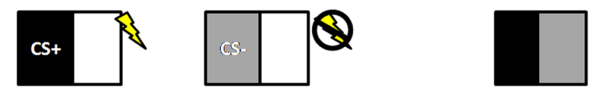

峞

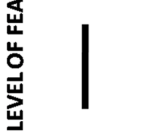

FEAR EXPRESSION

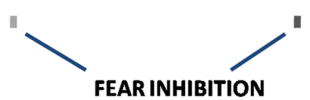

D STIMULUS GENERALIZATION

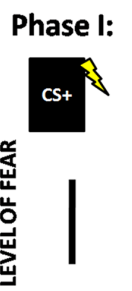

FEAR EXPRESSION
Phase II:
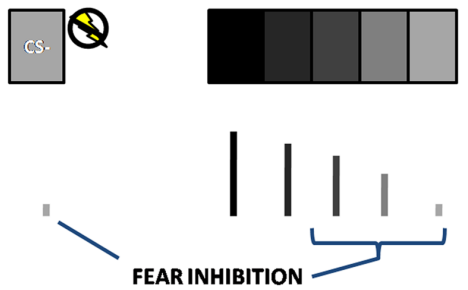

FIGURE 1 | Schematic depictions of four different fear-inhibition paradigms; (A) Extinction, (B) Simple Discrimination, (C) Conditional Discrimination, and (D) Stimulus Generalization. CS + = Reinforced Conditioned Stimulus; CS $-=$ Non-reinforced Conditioned Stimulus. In fear extinction paradigms (A), a stimulus that was paired with an aversive stimulus (the CS+) during the initial phase is then repeatedly presented without the US in the next phase of the experiment, so that it no longer elicits a fear response. In the simple discrimination paradigm (B), the CS+ is intermingled with a separate stimulus that is not paired with the US (CS-). In a conditional discrimination experiment (C), the US occurs depending on the presence of the CS+ when it is combined with a neutral $(X)$ cue, which is also combined with the CS- to predict the absence of the US. In the next phase of the experiment, presentation of CS+ and CS- together, without the shared cue $(X)$ results in a reduced fear response compared to the response to CS+. In a stimulus generalization experiment (D), after the initial conditioning, the second phase of the experiment presents iterations of CSs that differ from the CS+ in small increments. The number of degrees required for discrimination is an indication of cue overgeneralization. 
of the conditioned inhibition design, avoids some of these limitations (Myers and Davis, 2004). In a conditional discrimination experiment, an aversive event occurs depending on the presence of the CS+ when it is combined with a neutral (X) cue (Wagner and Rescorla, 1972). This cue is also combined with the CS- to predict the absence of the US (Figure 1C). In a critical subsequent test trial, presentation of CS+ and CS- together, without the shared cue (X) results in a reduced fear response compared to the response to CS+. This is referred to as the transfer test, when the inhibitory properties of the CS- are actively transferred to the combined CS+/CS- cue (Myers and Davis, 2004; Jovanovic et al., 2005).

The current review will focus on extinction, simple discrimination, and conditional discrimination methods of fear inhibition, as these have been more thoroughly investigated using psychophysiological techniques. The final paradigm, stimulus generalization is a very novel approach to studying fear inhibition and has only been recently used in patients with panic disorder (Lissek et al., 2010), and there are no published studies to date that have tested stimulus generalization in PTSD. This paradigm is promising because it assesses both the subjects' ability to detect subtle differences between danger and safety on a continuum, and their ability to show reduction of fear once the discrimination occurs (Lissek et al., 2010).

Both extinction tests and differential conditioning paradigms focus on active suppression of fear responses through learned safety signals; while fear itself may only involve subcortical areas of the brain located primarily in the limbic circuitry, safety signals may require a cognitive, cortical component (Bremner et al., 2005; Weike et al., 2008). This premise is supported by data from our lab showing that awareness of the association between the CS and the US is necessary for inhibiting fear responses (Jovanovic et al., 2006). Furthermore, a recent study by Weike et al. (2008) examined the temporal domain of fear conditioning with a danger and safety signal and found that safety signal processing was slower than danger processing. The authors argued that top-down cognitive processes are involved in responses to safety signals which accounts for the latency in response.

We have recently used extinction, simple discrimination, and conditional discrimination paradigms in a highly traumatized civilian population from inner-city Atlanta (Jovanovic et al., 2010a,b; Norrholm et al., 2011). Data from our study on extinction (Norrholm et al., 2011) suggest that the early phase of extinction is predicted by the level of fear expression to the CS+ (i.e., the danger signal) at the end of acquisition. It is this fear expression during early extinction that is exaggerated in PTSD subjects compared to traumatized non-PTSD controls (see Figure 2A). On the other hand, a high degree of fear remaining during late extinction is related to impaired inhibition, as it is best predicted by responses to the CS- (i.e., safety signal) at the end of acquisition (Norrholm et al., 2011). Figure 2B shows simple discrimination between the $\mathrm{CS}+$ and the CS- during late acquisition between PTSD subjects and controls. Although PTSD subjects are slower in developing the discrimination, by the final phase of conditioning both groups show higher levels of fear-potentiated startle to the CS+ than the CS-; however, PTSD subjects demonstrate higher levels of fear to both stimuli (Norrholm et al., 2011). The final paradigm, conditional discrimination, measures fear inhibition to the safety signal by

\section{A EXTINCTION}

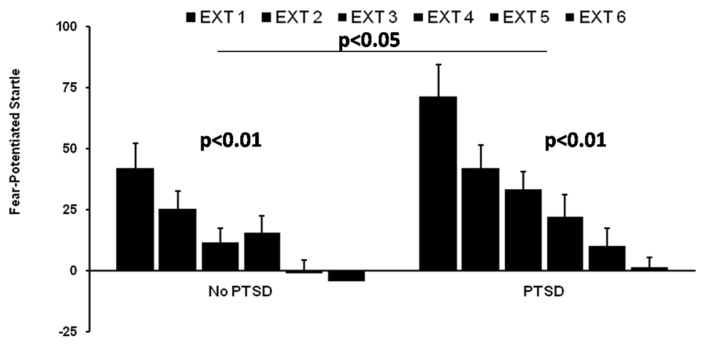

B SIMPLE DISCRIMINATION

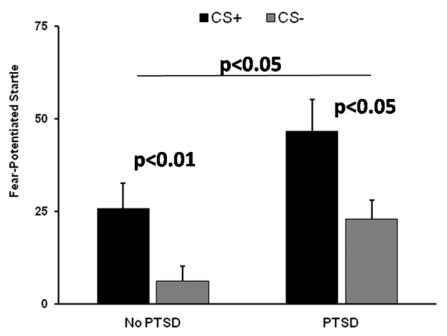

C CONDITIONAL DISCRIMINATION

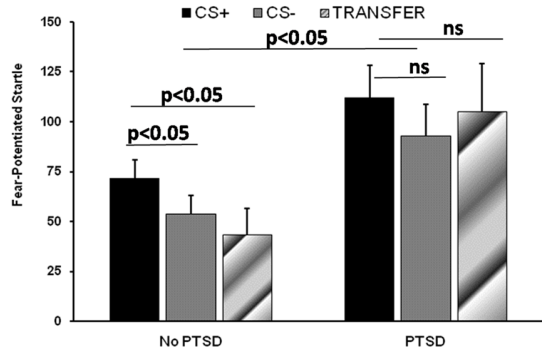

FIGURE 2 | Fear-inhibition data from our studies on a traumatized civilian population. (A) Extinction, adapted from (Norrholm et al., 2011); (B) Simple Discrimination, adapted from (Norrholm et al., 2011); (C) Conditional Discrimination, adapted from (Jovanovic et al., 2010b). EXT, Extinction Block; PTSD, Posttraumatic stress disorder; CS+, Reinforced Conditioned Stimulus; CS-, Non-reinforced Conditioned Stimulus.

testing the reduction of fear-potentiated startle on the transfer test. We used this paradigm in combat veterans (Jovanovic et al., 2009) and traumatized civilian population (Jovanovic et al., 2010b) and have found that individuals who met criteria for PTSD had higher potentiation of the startle response to the CS- than traumatized controls and did not transfer safety on the test trial (Figure 2C).

While some data with combat veterans suggest that impaired fear inhibition may be an acquired trait (Milad et al., 2008), that is associated with current symptom severity (Jovanovic et al., 2009), other studies have reported that heightened fear responses and decreased inhibition of fear may be predictors of the disorder. A prospective study of police academy cadets found that greater skin conductance responses to threatening stimuli and slower habituation prior to trauma exposure were predictive of PTSD symptom severity after trauma exposure (Pole et al., 2009). A similar prospective study with firefighters found that reduced extinction of fear conditioned responses examined before the index trauma explained almost a third of the symptoms in later traumatized 
individuals (Guthrie and Bryant, 2006). On the other hand, a recent study of Vietnam veterans and their twins found that PTSD subjects did not have impaired extinction learning, but rather had less extinction retention on the day after acquisition and extinction compared to veterans without PTSD (Milad et al., 2008). Furthermore, impaired retention of extinction appeared to be an acquired trait related to the disorder since the twins of the PTSD subjects did not show the same impairment. It is possible that a decreased ability to inhibit fear is a risk factor for developing the disorder and contributes to the maintenance of the disorder, while decreased extinction retention is a state resulting from the disorder - given that these fear-inhibition phenotypes may have different neural underpinnings this would explain the above studies. Extinction learning requires inhibition of the fear circuitry by the prefrontal cortex (PFC; Phelps et al., 2004); whereas discrimination between danger and safety cues, and recall of extinction may also require activation of the hippocampus (Milad et al., 2007b). Given that both extinction and differential conditioning are dependent on the PFC, this review will focus on this region as a primary locus in fear-inhibition neurocircuitry.

\section{INHIBITION NEUROCIRCUITRY AS A TARGET OF INVESTIGATION}

The PFC has long been thought to play a role in behavioral inhibition. More than a decade ago, animal studies reported that lesions of the medial PFC (mPFC) prior to original fear conditioning retard extinction to a tone (Morgan et al., 1993). Recent studies have demonstrated that neurons in the PFC may have inhibitory action on the amygdala (Grace and Rosenkranz, 2002; Phelps et al., 2004). The PFC can be subdivided into medial and orbitofrontal PFC. The anterior cingulate cortex (ACC), which is also part of the PFC, has both rostral and dorsal components which may play different roles in the expression and inhibition of fear, as will be discussed in greater detail below. Figure 3 shows the medial regions of the PFC most involved in inhibitory processes (Figure 3A), including the ventral and dorsal PFC and the ACC (Figure 3B).
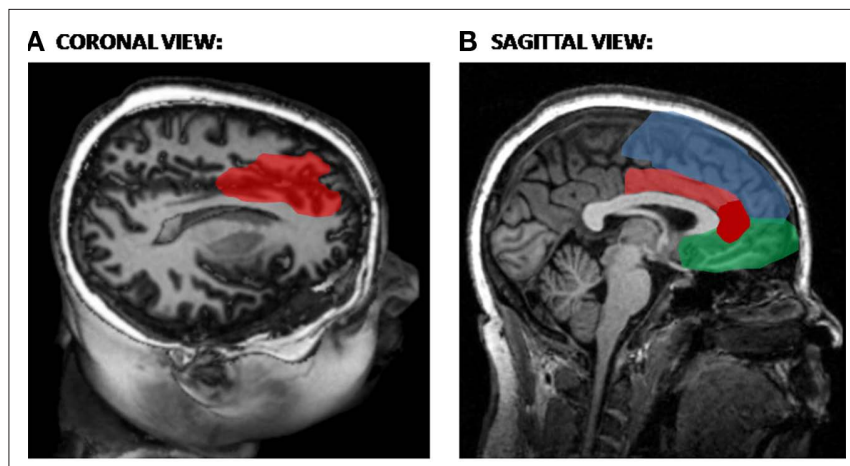

RED=medial Prefrontal Cortex (mPFC)

RED=anterior cingulate cortex (ACC) DARK RED = rostral ACC GREEN=ventromedial PFC BLUE=dorsomedial PFC

FIGURE 3 | Structural magnetic resonance image (MRI) showing areas involved in inhibition. (A) Coronal view showing location of medial areas in red. (B) Sagittal view showing prefrontal cortical areas.
Neuroimaging studies in humans have used several paradigms that activate the PFC; the simplest and most commonly used tasks involve response inhibition. In such tasks, the participant is presented a stimulus indicating that a response is required, for example, to press a button when a letter appears on the monitor. This is referred to as a "Go" signal. On a minority of trials, however, the participant is required to either withhold a response during a "NoGo" signal (the Go/NoGo task) or stop responding once they have begun the execute the action during a "Stop" signal (the Stop task; Hester et al., 2004; Eagle et al., 2008). The Go/NoGo task has been used in subjects with PTSD with electroencephalogram (EEG) evoked-potentials (Wu et al., 2010) and functional magnetic resonance imaging (fMRI) measures (Carrion et al., 2008; Falconer et al., 2008). This task reliably indicates decreased activation in PTSD subjects compared to controls in the rostral ACC, located at the genu of the corpus callosum (see Figure 3B). The advantage of this task is that it is very simple to administer in both behavioral and neuroimaging studies, and may provide insight into deficits in inhibiting limbic activity. Although a more general impairment in inhibitory processes mediated by the rACC may very well be an underlying abnormality associated with several psychiatric disorders, the deficits in inhibiting fear responses appear to be uniquely associated with re-experiencing and hyper-arousal symptoms of PTSD (Norrholm and Jovanovic, 2010). Further support for the utility of this paradigm comes from a study predicting positive treatment outcomes in PTSD patients with greater $\mathrm{rACC}$ volumes (Bryant et al., 2008).

A well known and frequently used example of a more complex inhibition task is the Stroop effect task, where the meaning of a word (such as the word "red") is in conflict with the color in which it is shown (for example, in blue ink). In this task, the subject is instructed to state the color of the ink while ignoring the interference from the word. Due to the conflict between the color and the word, reaction times are delayed, providing a measure of the cognitive inhibition (Stroop, 1935), and activating the ACC (Pardo et al., 1990; Bremner et al., 2004). The Stroop task can also be adapted to use with emotion-relevant stimuli, in which the emotional content of a word competes with the cognitive content and must be ignored. This task also activates the ACC, but in an area distinct from the strictly cognitive interference tasks (Whalen et al., 1998, 2006). Emotionally relevant stimuli appear to be processed by the rostral or subgenual area of the ACC (Shin et al., 2005), which is anterior to the genu of the corpus callosum. Furthermore, this specific region of the PFC, the rostral ACC, is involved in amygdala regulation (Etkin et al., 2006).

Neuroimaging studies using fear conditioning paradigms demonstrate that fear acquisition and extinction of fear also activate the PFC, specifically the ventromedial (vmPFC; Phelps et al., 2004; Reinhardt et al., 2010). Recent developments in the spatial resolution of neuroimaging techniques have resulted in more fine-tuned examinations of this area of the brain. As mentioned above, the rostral or subgenual regions of the ACC are activated during the presentation of emotional stimuli; these areas are also activated during the regulation of fear (Phelps et al., 2004; Schiller et al., 2008). There are several lines of evidence that this region of the vmPFC is associated with inhibition of fear. For example, fMRI data 
indicate increased activation during an extinction recall task that is presented after extinction learning has occurred (Phelps et al., 2004; Milad et al., 2007b). vmPFC is also activated during fear reversal tasks in which the CS contingencies are switched after acquisition so that a previously conditioned danger cue (CS+) becomes the new safety cue (CS-; Schiller et al., 2008). Morphometric data show that the thickness of vmPFC cortical tissue is correlated with extinction retention (Milad et al., 2005; Hartley et al., 2011). Functional and morphometric data support the rostral ACC as an anatomical substrate for fear inhibition, however, similarly acquired functional and morphometric data suggest that dorsal ACC activity underlies fear acquisition and fear expression (Milad et al., 2007a). Given that this area is also implicated in cognitive tasks (Shin et al., 2007), it may be activated by the active learning that occurs during fear acquisition, rather than by the fear itself. However, given that this area has been associated with fear as well as other noxious stimuli such as pain (Vogt et al., 2003), it may be more centrally involved in the expression of negative affect and not simply activated by general learning.

Several studies have indicated that this inhibitory neurocircuit is dysregulated in PTSD patients. Evidence suggests that a hallmark of PTSD neurobiology is exaggerated amygdala activity during fearful stimulation coupled with reduced top-down control of the amygdala by the PFC (Liberzon et al., 1999; Rauch et al., 2000, 2006; Shin et al., 2004; Liberzon and Martis, 2006). Furthermore, functional neuroimaging studies that have examined connectivity between PFC and the amygdala have demonstrated impaired inhibition of the amygdala in PTSD (Lanius et al., 2004). The emergence of MRIs with greater special resolution allows for more precise descriptions of these neural substrates. A recent meta-analyses of imaging studies during emotion processing in PTSD, social anxiety, and specific phobia indicated that the rostral ACC is less active in PTSD patients relative to controls; an effect not found in other anxiety disorders (Etkin and Wager, 2007). Furthermore, deficient activation of the rostral ACC has been observed in women with sexual trauma-related PTSD by coupling the the Emotional Stroop task with neuroimaging techniques (Bremner et al., 2004). Similar effects were also observed in combat veterans (Shin et al., 2001). Decreased activation of this area may be a risk factor for psychopathology: a recent study of children with depressed parents revealed a lack of ACC activation to the Emotional Stroop (Mannie et al., 2008). There has been a paucity of studies investigating fear conditioning in PTSD patients using neuroimaging methodologies. One study using positron emission tomography (PET) during fear acquisition and extinction, demonstrated heightened amygdala activity in PTSD patients relative to controls during the acquisition phase with lower ACC function during the extinction phase (Bremner et al., 2005). The differential involvement of the ACC subcomponents has been further elaborated in more recent studies. For example, a recently published study that tested extinction recall in an fMRI task demonstrated increased activation of the dorsal ACC (associated with learning) and decreased activation of the vmPFC (which includes the rostral ACC) in PTSD patients (Rougemont-Bücking et al., 2011). Finally, as previously mentioned, the rostral ACC is hypo-activated during Go/NoGo inhibition tasks (Carrion et al., 2008; Falconer et al., 2008).
To summarize the neuroimaging findings to date, the rostral ACC is involved in (1) response inhibition tasks, (2) emotion regulation tasks, (3) inhibition of fear, and (4) is hypo-active in PTSD. These data suggest that this specific circuit represents a compelling target for translational investigations of PTSD and anxiety, as a biomarker predictive of PTSD and anxiety disorder vulnerability, treatment response, or as a treatment outcome measure in itself.

\section{INHIBITION NEUROCIRCUITRY AND IMPLICATIONS FOR TREATMENT RESPONSE}

Currently, the most effective therapy for PTSD appears to be psychotherapy, such as cognitive-behavioral therapy, which employs imaginal, in vivo, or virtual reality exposure to trauma cues (Rothbaum and Schwartz, 2002). The repeated exposure to feared cues without the negative events associated with the trauma, gradually leads to a reduction in symptoms. Clearly, active fear inhibition is critically involved in this treatment type. Although extant treatment approaches are not tailored to an individual patient's symptom profile, future treatment strategies for PTSD may be governed by a shift toward personalized medicine (see Norrholm and Jovanovic, 2010). The identification of particular risk factors such as genotype or gene expression, as well as the assessment of intermediate phenotypes specific to PTSD may dictate which treatment regimens will be most effective for a particular patient.

It now appears that some forms of dysregulated fear inhibition, such as impaired conditioned fear extinction, may be a vulnerability factor for the development of PTSD (Guthrie and Bryant, 2006; Pole et al., 2009), while other forms of impaired inhibition, such as danger/safety signal discrimination, may be associated with current symptom state, (Jovanovic et al., 2009). In addition, impaired fear inhibition that manifests itself as disrupted extinction recall may represent acquired traits of the disorder (Milad et al., 2008). The difference between these paradigms may lie in the involvement of the hippocampus in the latter (Milad et al., 2007c); which early studies have found to be decreased in PTSD subjects (Bremner et al., 1995) possibly as a result of the trauma and associated stress (Bremner, 2001). However, some have argued that smaller hippocampal volume is a risk factor for PTSD (Pitman, 2001; Gilbertson et al., 2002). These issues can only be resolved with a prospective study examining neural volume before and after onset of PTSD. Regardless of whether fear inhibition is impaired prior to PTSD or develops as part of the disorder itself, it may be modifiable with treatment.

Clinically, fear inhibition has not yet been tested with regard to treatment response. The lack of these studies is partly due to the difficulty of testing de novo learning in a repeated design. For example, improvements in fear inhibition after treatment may not be due to treatment efficacy, but rather to a practice effect from patients remembering the previously administered training paradigms. A recent study with fear acquisition and fear extinction tests spaced 12 weeks apart demonstrated good test-retest reliability on these measures (Zeidan et al., 2011); this is a crucial first step to developing treatment outcome measures.

Although treatment outcome and psychophysiological fearinhibition measures have not been actively examined concurrently, several studies have begun to investigate the relationship between pre-treatment neural function and subsequent treatment response. In PTSD, one study revealed that larger rostral ACC 
volume predicted positive outcomes to cognitive-behavior therapy (Bryant et al., 2008). Furthermore, this brain area has been linked to treatment response in depression (Pizzagalli et al., 2001; Pizzagalli, 2011). The ventral area immediately below the corpus callosum has been used as a target in deep brain stimulation to relieve depression (Holtzheimer and Mayberg, 2010), with long-term positive outcomes (Kennedy et al., 2011).

There is an emerging body of literature assessing structural and functional changes in the neural underpinnings of PTSD with treatment. An early study using single photon emission computed tomography (SPECT) imaging pre- and post-treatment with selective serotonin reuptake inhibitors (SSRIs), found significant changes in ACC and hippocampus after 12 weeks of treatment (Carey et al., 2004). More recent studies using fMRI before and after psychotherapy for depression have indicated changes in prefrontal areas (Dichter et al., 2010; Ritchey et al., 2011).

\section{FUTURE DIRECTIONS: CAN WE INCREASE NEURAL INHIBITION OF FEAR?}

Several exciting and novel avenues have been revealed for the further exploration and development of neurobiologically based, translational studies of PTSD and trauma-related disorders. We are currently well-poised to investigate these avenues as a means of developing better diagnostic tools based on novel neurobiological intermediate phenotypes. An obvious first step is to test fear inhibition before and after treatment in order to improve existing predictors of treatment response. This will also allow for the exploration of potential individual differences that contribute to positive treatment outcomes and aid in personalization on treatment strategies. Another goal is to track treatment efficacy in responders.

In addition to increased exploration of the putative fearinhibition phenotype with respect to treatment, we also need to investigate treatment-related changes in brain neurocircuitry and structure. As previously described, fMRI has been successfully employed in depressed patients with significant treatment results (Ritchey et al., 2011). Given the specificity of the brain areas that are related to fear inhibition in PTSD, namely, the rostral ACC,

\section{REFERENCES}

Alim, T. N., Graves, E., Mellman, T. A., Aigbogun, N., Gray, E., Lawson, W., and Charney, D. S. (2006). Trauma exposure, posttraumatic stress disorder and depression in an AfricanAmerican primary care population. J. Natl. Med. Assoc. 98, 1630-1636.

APA. (1994). Diagnostic and Statistical Manual of Mental Disorders (DSM-IV). Washington, DC: American Psychiatric Association.

Binder, E. B., Bradley, R. G., Liu, W., Epstein, M. P., Deveau, T. C., Mercer, K. B., Tang, Y., Gillespie, C. F., Heim, C. M., Nemeroff, C. B., Schwartz, A. C., Cubells, J. F., and Ressler, K. J. (2008). Association of FKBP5 polymorphisms and childhood abuse with risk of posttraumatic stress disorder symptoms in adults. JAMA 299, 1291-1305.
Bremner, J. D. (2001). Hypotheses and controversies related to effects of stress on the hippocampus: an argument for stress-induced damage to the hippocampus in patients with posttraumatic stress disorder. Hippocampus 11, 75-81; discussion 82-74.

Bremner, J. D., Randall, P. R., Scott, T. M., Bronen, R. A., Delaney, R. C., Seibyl, J. P., Southwick, S. M., Mccarthy, G., Charney, D. S., and Innis, R. B. (1995). MRI-based measurement of hippocampal volume in patients with combat-related posttraumatic stress disorder. Am. J. Psychiatry 152, 973-981.

Bremner, J. D., Vermetten, E., Schmahl, C., Vaccarino, V., Vythilingam, M., Afzal, N., Grillon, C., and Charney, D. S. (2005). Positron emission tomographic imaging of neural correlates of a fear acquisition and extinction

simple inhibition tasks such as the Go/NoGo can be administered before and after treatment to detect changes in the volume, activity, and connectivity of this area. Furthermore, the use of fMRI tasks in concert with fear-inhibition paradigms (e.g., extinction and differential conditioning) with PTSD patients is in its infancy and we anticipate several emerging studies using these methods.

Finally, future studies should be focused on strengthening the activation of the rostral ACC, especially during the presentation of fear-related stimuli. The aforementioned fMRI studies from the depression literature suggest that the PFC represents a relatively neuroplastic brain region with the potential for treatmentrelated modifications in activity (e.g., successfully attenuating amygdala-driven fear responses); these findings offer great promise to improving on the available treatments for PTSD. Novel treatment approaches have employed computerized tasks in order to train patients to generate the anticipated (or therapeutic) response. For example, attention bias training has been used successfully with many anxiety disorders to train patients' attention away from negative stimuli and, as such, significantly decrease symptom severity (Reese et al., 2010; Rozenman et al., 2011). Similar computerized tasks or games can be devised to bolster fear-inhibition training. For example, exposure therapy, which is one of the most successful psychotherapeutic approaches to PTSD, may in fact produce its effects by increasing fear inhibition. Given that exposure therapy is based on extinction learning, which activates the vmPFC, this premise would provide a likely neural mechanism of action. Facilitating extinction, either pharmacologically or behaviorally, may produce therapeutic, beneficial modifications to underlying neural connectivity and thus increase inhibition of fear.

\section{ACKNOWLEDGMENTS}

Dr. Jovanovic has funding from NIMH (F32 MH070129). Dr. Norrholm has research support from the National Alliance for Research on Schizophrenia and Depression (NARSAD), the Department of Defense (DOD)/Congressionally Directed Medical Research Program (CDMRP, award \#W81XWH-08-2-0170), and the Emory University Research Committee.

paradigm in women with childhood sexual-abuse-related post-traumatic stress disorder. Psychol. Med. 35, 791-806.

Bremner, J. D., Vermetten, E., Vythilingam, M., Afzal, N., Schmahl, C., Elzinga, B., and Charney, D. S (2004). Neural correlates of the classic color and emotional stroop in women with abuse-related posttraumatic stress disorder. Biol. Psychiatry 55, 612-620.

Breslau, N., Kessler, R. C., Chilcoat, H. D., Schultz, L. R., Davis, G. C., and Andreski, P. (1998). Trauma and posttraumatic stress disorder in the community: the 1996 Detroit area survey of trauma. Arch. Gen. Psychiatry 55, 626-632.

Bryant, R. A., Felmingham, K., Whitford, T. J., Kemp, A., Hughes, G., Peduto, A., and Williams, L. M. (2008). Rostral anterior cingulate volume predicts treatment response to cognitivebehavioural therapy for posttraumatic stress disorder. J. Psychiatry Neurosci. 33, 142-146.

Carey, P., Warwick, J., Niehaus, D., Van Der Linden, G., Van Heerden, B., Harvey, B., Seedat, S., and Stein, D. (2004). Single photon emission computed tomography (SPECT) of anxiety disorders before and after treatment with citalopram. BMC Psychiatry 4, 30. doi: 10.1186/1471-244X-4-30

Carrion, V. G., Garrett, A., Menon, V. Weems, C. F., and Reiss, A. L. (2008). Posttraumatic stress symptoms and brain function during a responseinhibition task: an fMRI study in youth. Depress. Anxiety 25, 514-526.

Charney, D. S. (2004). Psychobiological mechanisms of resilience and vulnerability: implications for successful 
adaptation to extreme stress. Am. J. Psychiatry. 161, 195-216.

Davis, M. (1990). Animal models of anxiety based on classical conditioning: the conditioned emotional response (CER) and the fear-potentiated startle effect. Pharmacol. Ther. 47, 147-165.

Dichter, G. S., Felder, J. N., and Smoski, M. J. (2010). The effects of brief behavioral activation therapy for depression on cognitive control in affective contexts: an fMRI investigation. J. Affect. Disord. 126, 236-244.

Eagle, D., Bari, A., and Robbins, T. (2008). The neuropsychopharmacology of action inhibition: cross-species translation of the stop-signal and go/no-go tasks. Psychopharmacology (Berl.) 199, 439-456.

Etkin, A., Egner, T., Peraza, D. M., Kandel, E. R., and Hirsch, J. (2006). Resolving emotional conflict: a role for the rostral anterior cingulate cortex in modulating activity in the amygdala. Neuron 51, 871-882.

Etkin,A., and Wager, T. (2007). Functional neuroimaging of anxiety: a metaanalysis of emotional processing in PTSD, social anxiety disorder, and specific phobia. Am. J. Psychiatry 164, 1476-1488.

Falconer, E., Bryant, R., Felmingham, K. L., Kemp, A. H., Gordon, E., Peduto, A., Olivieri, G., and Williams, L. M. (2008). The neural networks of inhibitory control in posttraumatic stress disorder. J. Psychiatry Neurosci. 33, 413-422.

Falls, W. A., Bakken, S., and Heldt, S. A. (1997). Lesions of the perirhinal cortex block conditioned excitation but not conditioned inhibition of fear. Behav. Neurosci. 111, 476-486.

Fanselow, M., and Ledoux, J. (1999). Why we think plasticity underlying Pavlovian fear conditioning occurs in the basolateral amygdala. Neuron 23, 229-232.

Gewirtz, J. C., Falls, W. A., and Davis, M. (1997). Normal conditioned inhibition and extinction of freezing and fear potentiated startle following electrolytic lesions of medial prefrontal cortex. Behav. Neurosci. 111, 712-726.

Gilbertson, M. W., Shenton, M. E., Ciszewski, A., Kasai, K., Lasko, N. B., Orr, S. P., and Pitman, R. K. (2002). Smaller hippocampal volume predicts pathologic vulnerability to psychological trauma. Nat. Neurosci. 5, 1242-1247.

Grace,A.A., and Rosenkranz, J.A. (2002). Regulation of conditioned responses of basolateral amygdala neurons. Physiol. Behav. 77, 489-493.

Grillon, C., and Ameli, R. (2001). Conditioned inhibition of fear-potentiated startle and skin conductance in humans. Psychophysiology 38, 807-815.

Grillon, C., and Davis, M. (1997). Fearpotentiated startle conditioning in humans: explicit and contextual cue conditioning following paired versus unpaired training. Psychophysiology 34, 451-458.

Guthrie, R. M., and Bryant, R. A. (2006). Extinction learning before trauma and subsequent posttraumatic stress. Psychosom. Med. 68, 307-311.

Hartley, C. A., Fischl, B., and Phelps, E. A. (2011). Brain structure correlates of individual differences in the acquisition and inhibition of conditioned fear. Cereb. Cortex. doi: 10.1093/cercor/bhq253. [Epub ahead of print].

Hester, R., Fassbender, C., and Garavan, H. (2004). Individual differences in error processing: a review and reanalysis of three event-related fMRI studies using the GO/NOGO task. Cereb. Cortex 14, 986-994.

Holtzheimer, P. E. III, and Mayberg, H. S. (2010). Deep brain stimulation for treatment-resistant depression. Am. J. Psychiatry 167, 1437-1444.

Jovanovic, T., Kazama, A., Bachevalier, J., and Davis, M. (2011). Impaired safety signal learning may be a biomarker of PTSD. Neuropharmacology. doi: 10.1016/j.neuropharm.2011.02.023. [Epub ahead of print].

Jovanovic, T., Keyes, M., Fiallos, A., Myers, K. M., Davis, M., and Duncan, E. (2005). Fear potentiation and fear inhibition in a human fear-potentiated startle paradigm. Biol. Psychiatry $57,1559-1564$.

Jovanovic, T., Norrholm, S. D., Blanding, N. Q., Davis, M., Duncan, E., Bradley, B., and Ressler, K. J. (2010a). Impaired fear inhibition is a biomarker of PTSD but not depression. Depress. Anxiety 27, 244-251.

Jovanovic, T., Norrholm, S. D., Blanding, N. Q., Phifer, J. E., Weiss, T., Davis, M., Duncan, E., Bradley, B., and Ressler, K. (2010b). Fear potentiation is associated with hypothalamicpituitary-adrenal axis function in PTSD. Psychoneuroendocrinology 35, 846-857.

Jovanovic, T., Norrholm, S. D., Fennell, J. E., Keyes, M., Fiallos, A. M., Myers, K. M., Davis, M., and Duncan, E. J. (2009). Posttraumatic stress disorder may be associated with impaired fear inhibition: relation to symptom severity. Psychiatry Res. 167, 151-160.

Jovanovic, T., Norrholm, S. D., Keyes, M., Fiallos, A., Jovanovic, S., Myers, K. M., Davis, M., and Duncan, E. J. (2006). Contingency awareness and fear inhibition in a human fear-potentiated startle paradigm. Behav. Neurosci. 120, 995-1004.
Kennedy, S. H., Giacobbe, P., Rizvi, S. J., Placenza, F. M., Nishikawa, Y., Mayberg, H. S., and Lozano, A. M. (2011). Deep brain stimulation for treatment-resistant depression: follow-up after 3 to 6 years. Am. J. Psychiatry 168, 502-510.

Kessler, R. C., Sonnega, A., Bromet, E. Hughes, M., and Nelson, C. B. (1995). Posttraumatic stress disorder in the national comorbidity survey. Arch. Gen. Psychiatry 52, 1048-1060.

Labar, K. S., Ledoux, J. E., Spencer, D. D. and Phelps, E. A. (1995). Impaired fear conditioning following unilateral temporal lobectomy in humans. J. Neurosci. 15, 6848-6855.

Lanius, R. A., Bluhm, R., Lanius, U., and Pain, C. (2006). A review of neuroimaging studies in PTSD: heterogeneity of response to symptom provocation. J. Psychiatr. Res. 40, 709-729.

Lanius, R.A., Williamson, P.C., Densmore, M., Boksman, K., Neufeld, R. W., Gati, J. S., and Menon, R. S. (2004). The nature of traumatic memories: a 4-T fMRI functional connectivity analysis. Am. J. Psychiatry 161, 36-44.

Liberzon, I., and Martis, B. (2006). Neuroimaging studies of emotional responses in PTSD. Ann. N. Y. Acad. Sci. 1071, 87-109.

Liberzon, I., Taylor, S. F., Amdur, R., Jung, T. D., Chamberlain, K. R., Minoshima, S., Koeppe, R. A., and Fig, L. M. (1999). Brain activation in PTSD in response to trauma-related stimuli. Biol. Psychiatry 45, 817-826.

Lissek, S., Powers, A. S., Mcclure, E. B. Phelps, E. A., Woldehawariat, G. Grillon, C., and Pine, D. S. (2005) Classical fear conditioning in the anxiety disorders: a meta-analysis. Behav Res. Ther. 43, 1391-1424.

Lissek, S., Rabin, S., Heller, R. E., Lukenbaugh, D., Geraci, M., Pine, D. S., and Grillon, C. (2010). Overgeneralization of conditioned fear as a pathogenic marker of panic disorder. Am. J. Psychiatry 167, 47-55.

Mannie, Z. N., Norbury, R., Murphy, S.E. Inkster, B., Harmer, C. J., and Cowen, P. J. (2008). Affective modulation of anterior cingulate cortex in young people at increased familial risk of depression. Br. J. Psychiatry 192, 356-361.

Mcteague, L. M., Lang, P. J., Laplante, M.-C., Cuthbert, B. N., Shumen, J. R. and Bradley, M. M. (2010). Aversive imagery in posttraumatic stress disorder: trauma recurrence, comorbidity, and physiological reactivity. Biol. Psychiatry 67, 346-356.

Milad, M. R., Orr, S. P., Lasko, N. B., Chang, Y., Rauch, S. L., and Pitman, R. K. (2008). Presence and acquired origin of reduced recall for fear extinc- tion in PTSD: results of a twin study. J. Psychiatr. Res. 42, 515-520.

Milad, M. R., Quinn, B. T., Pitman, R. K., Orr, S. P., Fischl, B., and Rauch, S. L. (2005). Thickness of ventromedial prefrontal cortex in humans is correlated with extinction memory. Proc. Natl. Acad. Sci. U.S.A. 102, 10706-10711.

Milad, M. R., Quirk, G. J., Pitman, R. K., Orr, S. P., Fischl, B., and Rauch, S. L. (2007a). A role for the human dorsal anterior cingulate cortex in fear expression. Biol. Psychiatry 62, 1191-1194.

Milad, M. R., Wright, C. I., Orr, S. P., Pitman, R. K., Quirk, G. J., and Rauch, S. L. (2007b). Recall of fear extinction in humans activates the ventromedial prefrontal cortex and hippocampus in concert. Biol. Psychiatry 62, 446-454.

Milad, M. R., Wright, C. I., Orr, S. P., Pitman, R. K., Quirk, G. J., and Rauch, S. L. (2007c). Recall of fear extinction in humans activates the ventromedial prefrontal cortex and hippocampus in concert. Biol. Psychiatry 62, 446-454.

Morgan, M. A., Romanski, L. M., and Ledoux, J. E. (1993). Extinction of emotional learning: contribution of medial prefrontal cortex. Neurosci. Lett. 163, 109-113.

Myers, K. M., and Davis, M. (2004). AX+, $\mathrm{BX}$ - discrimination learning in the fear-potentiated startle paradigm: possible relevance to inhibitory fear learning in extinction. Learn. Mem. 11, 464-475.

Myers, K. M., Ressler, K. J., and Davis, M. (2006). Different mechanisms of fear extinction dependent on length of time since fear acquisition. Learn. Mem. 13, 216-223.

Myers, K. M., Toufexis, D. J., Winslow, J. T., Jovanovic, T., Norrholm, S. D., Duncan, E., and Davis, M. (eds). (2009). Measurement of Fear Inhibition in Rats, Monkeys, and Humans with and without Posttraumatic Stress Disorder, Using the AX+, BX- Paradigm. New York City: The Guilford Press.

Norrholm, S. D., and Jovanovic, T. (2010). Tailoring therapeutic strategies for treating posttraumatic stress disorder symptom clusters. Neuropsychiatr. Dis. Treat. 6, 1-16.

Norrholm, S. D., Jovanovic, T., Olin, I. W., Sands, L. A., Karapanou, I., Bradley, B., and Ressler, K. J. (2011). Fear extinction in traumatized civilians with posttraumatic stress disorder: relation to symptom severity. Biol. Psychiatry 69, 556-563.

Norrholm, S. D., Jovanovic, T., Vervliet, B., Myers, K. M., Davis, M., Rothbaum, B. O., and Duncan, E. J. (2006). Conditioned fear extinction and reinstatement in a human fear-potentiated 
startle paradigm. Learn. Mem. 13, 681-685.

Norrholm, S. D., and Ressler, K. J. (2009). Genetics of anxiety and traumarelated disorders. Neuroscience 164, 272-287.

Pardo, J. V., Pardo, P. J., Janer, K. W., and Raichle, M. E. (1990). The anterior cingulate cortex mediates processing selection in the Stroop attentional conflict paradigm. Proc. Natl. Acad. Sci. U.S.A. 87, 256-259.

Pavlov, I. P. (1927). Conditioned Reflexes. London: Oxford University Press.

Phelps, E. A., Delgado, M. R., Nearing, K. I., and Ledoux, J. E. (2004). Extinction learning in humans: role of the amygdala and vmPFC. Neuron 43, 897-905.

Pitman, R. K. (2001). Hippocampal dimunition in PTSD: more (or less?) than meets the eye. Hippocampus 11,73-74.

Pizzagalli, D. A. (2011). Frontocingulate dysfunction in depression: toward biomarkers of treatment response. Neuropsychopharmacology 36, 183-206.

Pizzagalli, D. A., Pascual-Marqui, R. D., Nitschke, J. B., Oakes, T. R., Larson, C. L., Abercrombie, H. C., Schaefer, S. M., Koger, J. V., Benca, R. M., and Davidson, R. J. (2001). Anterior cingulate activity as a predictor of degree of treatment response in major depression: evidence from brain electrical tomography analysis. Am. J. Psychiatry 158, 405-415.

Pole, N., Neylan, T. C., Otte, C., HennHasse, C., Metzler, T. J., and Marmar, C. R. (2009). Prospective prediction of posttraumatic stress disorder symptoms using fear potentiated auditory startle responses. Biol. Psychiatry 65, 235-240.

Rauch, S. L., Shin, L. M., and Phelps, E. A. (2006). Neurocircuitry models of posttraumatic stress disorder and extinction: human neuroimaging research-past, present, and future. Biol. Psychiatry 60, 376-382.

Rauch, S. L., Whalen, P. J., Shin, L. M., Mcinerney, S. C., Macklin, M. L., Lasko, N. B., Orr, S. P., and Pitman, R. K. (2000). Exaggerated amygdala response to masked facial stimuli in posttraumatic stress disorder: a func- tional MRI study. Biol. Psychiatry 47, 769-776.

Reese, H. E., Mcnally, R. J., Najmi, S., and Amir, N. (2010). Attention training for reducing spider fear in spiderfearful individuals. J. Anxiety Disord. 24, 657-662.

Reinhardt, I., Jansen, A., Kellermann, T., Schuppen, A., Kohn, N., Gerlach, A. L., and Kircher, T. (2010). Neural correlates of aversive conditioning: development of a functional imaging paradigm for the investigation of anxiety disorders. Eur. Arch. Psychiatry Clin. Neurosci. 260, 443-453.

Ressler, K. J., Bradley, B., Mercer, K. B. Deveau, T. C., Smith, A. K., Gillespie, C. F., Nemeroff, C. B., Cubells, J. F., and Binder, E. B. (2010). Polymorphisms in CRHR1 and the serotonin transporter loci: gene $\mathrm{x}$ gene $\mathrm{x}$ environment interactions on depressive symptoms. Am. J. Med. Genet. B Neuropsychiatr. Genet. 153B, 812-824.

Ritchey, M., Dolcos, F., Eddington, K. M., Strauman, T. J., and Cabeza, R. (2011). Neural correlates of emotional processing in depression: changes with cognitive behavioral therapy and predictors of treatment response. $J$. Psychiatr. Res. 45, 577-587.

Rothbaum, B. O., and Schwartz, A. C. (2002). Exposure therapy for posttraumatic stress disorder. Am. J. Psychother. $56,59$.

Rougemont-Bücking, A., Linnman, C. Zeffiro, T. A., Zeidan, M. A., LebronMilad, K., Rodriguez-Romaguera, J., Rauch, S. L., Pitman, R. K., and Milad, M. R. (2011). Altered processing of contextual information during fear extinction in PTSD: an fMRI study. CNS Neurosci. Ther. 17, 227-236.

Rozenman, M., Weersing, V. R., and Amir N. (2011). A case series of attention modification in clinically anxious youths. Behav. Res. Ther. 49, 324-330.

Schiller, D., Levy, I., Niv, Y., Ledoux, J. E. and Phelps, E. A. (2008). From fear to safety and back: reversal of fear in the human brain. J. Neurosci. 28, 11517-11525.

Schwartz, A.C., Bradley, R. L., Sexton, M., Sherry, A., and Ressler, K. J. (2005). Posttraumatic stress disorder among African Americans in an inner city mental health clinic. Psychiatr. Serv. 56, 212-215

Shin, L. M., Bush, G., Whalen, P. J. Handwerger, K., Cannistraro, P. A., Wright, C. I., Martis, B., Macklin, M. L., Lasko, N. B., Orr, S. P., Pitman, R. K., and Rauch, S. L. (2007). Dorsa anterior cingulate function in posttraumatic stress disorder. J. Trauma Stress 20, 701-712.

Shin, L. M., Orr, S. P., Carson, M. A. Rauch, S. L., Macklin, M. L., Lasko, N. B., Peters, P. M., Metzger, L. J., Dougherty, D. D., Cannistraro, P. A., Alpert, N. M., Fischman, A. J., and Pitman, R. K. (2004). Regional cerebral blood flow in the amygdala and medial prefrontal cortex during traumatic imagery in male and female vietnam veterans with PTSD. Arch. Gen. Psychiatry 61, 168-176.

Shin, L. M., Whalen, P. J., Pitman, R. K. Bush, G., Macklin, M. L., Lasko, N. B. Orr, S.P., Mcinerney, S. C., and Rauch, S. L. (2001). An fMRI study of anterior cingulate function in posttraumatic stress disorder. Biol. Psychiatry 50, 932-942.

Shin, L. M., Wright, C. I., Cannistraro, P. A., Wedig, M. M., Mcmullin, K. Martis, B., Macklin, M. L., Lasko, N. B., Cavanagh, S. R., Krangel, T. S., Orr, S. P., Pitman, R. K., Whalen, P. J., and Rauch, S. L. (2005). A functional magnetic resonance imaging study of amygdala and medial prefrontal cortex responses to overtly presented fearful faces in posttraumatic stress disorder. Arch. Gen. Psychiatry 62, 273-281.

Stroop, J. R. (1935). Studies of interference in serial verbal reactions. J. Exp. Psychol. 18, 643-661.

Vogt, B. A., Berger, G. R., and Derbyshire, S. W. G. (2003). Structural and functional dichotomy of human midcingulate cortex. Eur. J. Neurosci. 18 3134-3144.

Wagner, A. R., and Rescorla, R. A. (1972) "Inhibition in Pavlovian conditioning: application of a theory," in Inhibition and Learning, eds. R. A. Boakes and M. S. Halliday (London: Academic Press), 301-336.

Weike, A. I., Schupp, H. T., and Hamm, A. O. (2008). In dubio pro defensio: initial activation of conditioned fear is not cue specific. Behav. Neurosci. $122,685-696$

Whalen, P. J., Bush, G., Mcnally, R. J., Wilhelm, S., Mcinerney, S. C., Jenike, M. A., and Rauch, S. L. (1998). The emotional counting stroop paradigm: a functional magnetic resonance imaging probe of the anterior cingulate affective division. Biol. Psychiatry 44, 1219-1228.

Whalen, P. J., Bush, G., Shin, L. M., and Rauch, S. L. (2006). The emotional counting Stroop: a task for assessing emotional interference during brain imaging. Nat. Protoc. 1, 293-296.

Wu, J., Ge, Y., Shi, Z., Duan, X., Wang, L., Sun, X., and Zhang, K. (2010). Response inhibition in adolescent earthquake survivors with and without posttraumatic stress disorder: a combined behavioral and ERP study. Neurosci. Lett. 486, 117-121.

Zeidan, M. A., Lebron-Milad, K. Thompson-Hollands, J., Im, J. J. Y., Dougherty, D. D., Holt, D. J., Orr S. P., and Milad, M. R. (2011). Testretest reliability during fear acquisition and fear extinction in humans. CNS Neurosci. Ther. doi: 10.1111/j.17555949.2011.00238.x. [Epub ahead of print].

Conflict of Interest Statement: The authors declare that the research was conducted in the absence of any commercial or financial relationships that could be construed as a potential conflict of interest.

Received: 27 April 2011; paper pending published: 27 June 2011; accepted: 11 July 2011; published online: 25 July 2011.

Citation: Jovanovic T and Norrholm SD (2011) Neural mechanisms of impaired fear inhibition in posttraumatic stress disorder. Front. Behav. Neurosci. 5:44. doi: 10.3389/ fnbeh.2011.00044

Copyright ( () 2011 Jovanovic and Norrholm. This is an open-access article subject to a non-exclusive license between the author and Frontiers Media SA, which permits use, distribution and reproduction in other forums, provided the original authors and source are credited and other Frontiers conditions are complied with. 